Check for updates

Cite this: RSC Adv., 2018, 8, 33980

\title{
Synthesis of a one-dimensional atomic crystal of vanadium selenide $\left(\mathrm{V}_{2} \mathrm{Se}_{9}\right) \dagger$
}

\author{
Seungbae Oh, $\xi^{\mathrm{a}}$ Sudong Chae, $\hbar^{\mathrm{a}}$ Bum Jun Kim, ${ }^{\mathrm{b}}$ Kyung Hwan Choi, ${ }^{\mathrm{b}}$ \\ Woo-Sung Jang, ${ }^{c}$ Jimin Jang, ${ }^{b}$ Yasmin Hussain, ${ }^{a}$ Dong Kyu Lee, ${ }^{d}$ \\ Young-Min Kim, (D) ${ }^{\text {ce }}$ Hak Ki Yu (D) ${ }^{* d}$ and Jae-Young Choi (D) *ab
}

\begin{abstract}
The synthesis and nanoscale dispersion of a new one-dimensional (1D) material, $\mathrm{V}_{2} \mathrm{Se}_{9}$, in which chainshaped molecular units with strong covalent bonds are assembled in a crystal structure via weak van der Waals attraction between chains, were successfully carried out. $\mathrm{V}_{2} \mathrm{Se}_{9}$ is synthesized by solid-state reaction and additional heat treatment. The synthesized $\mathrm{V}_{2} \mathrm{Se}_{9}$ has excellent thermal stability up to $400{ }^{\circ} \mathrm{C}$ and has been experimentally confirmed to be dispersed up to $\sim 20 \mathrm{~nm}$ or less through a specific solvent dispersion. The covalently bonded $\mathrm{V}_{2} \mathrm{Se}_{9}$ chain, when isolated from its bulk material, is expected to exhibit unique quantum physical properties owing to the confinement of electrons in the 1D chain structure and the absence of inter-chain interactions, as demonstrated in the case of graphene and other $2 \mathrm{D}$ materials. Therefore, the novel $1 \mathrm{D}$ material of $\mathrm{V}_{2} \mathrm{Se}_{9}$, as an extension of the current 2D material, is expected to create a new class of materials that will be of significant interest to the materials science and nanotechnology communities for new device applications.
\end{abstract}

Received 30th July 2018

Accepted 24th September 2018

DOI: $10.1039 / \mathrm{c} 8 \mathrm{ra06398b}$

rsc.li/rsc-advances fabrication of reliable semiconductor devices. ${ }^{\mathbf{1 0}}$ Other $2 \mathrm{D}$ semiconductor materials, such as transition metal dichalcogenides (TMDCs) and black phosphor, have appropriate bandgaps (1-2 eV), but their stability and/or carrier mobility are limited. ${ }^{\mathbf{1 1 - 1 3}}$ More importantly, decreased transport properties at the nanoscale are still unavoidable in current 2D materials, because they have dangling bonds at the side edges and domain boundaries. ${ }^{14}$ Carbon nanotubes (CNTs, representative 1D materials), which exhibit high electrical mobility, chemical stability, and mechanical strength, have been extensively studied for use as building blocks of transistors, sensors, and nanocomposites. ${ }^{15-17}$ However, the wide range of electronic structures that arise from the different chirality of CNTs hinders the fabrication of nanoelectronic devices with uniform performance. Therefore, it is necessary to either achieve separation of single-chirality CNTs from bulk CNTs or control the chirality during the growth of CNTs. ${ }^{18}$ Although several studies have addressed these issues, it is still challenging to obtain singlechirality CNTs.

To overcome the problems of existing low-dimensional materials, researches on new 1D materials have been carried out. For example, extensive studies for bulk synthesis and atomic scale dispersion of $\mathrm{LiMo}_{3} \mathrm{Se}_{3}$ and $\mathrm{Mo}_{6} \mathrm{~S}_{9-x} \mathrm{I}_{x}$ have been reported. ${ }^{19-33}$ Recently, quantum confinement effect of $\mathrm{LiMo}_{3}$ $\mathrm{Se}_{3}$ and bio-stability of $\mathrm{Mo}_{6} \mathrm{~S}_{9-x} \mathrm{I}_{x}$ were demonstrated and their applications have been explored..$^{24,25,29,33}$ In addition, device application using new $1 \mathrm{D}$ materials, such as $\mathrm{Sb}_{2} \mathrm{Se}_{3}$ (optoelectronic devices using the property of effectively reducing exciton decay because of absence of dangling bonds) and $\mathrm{VS}_{4}$ 
(electrochemical energy storage using the space between 1D nanostructures) have been reported. ${ }^{34-36}$ Therefore, there is a definite scope for identification, synthesis, and characterization of new 1D materials.

By understanding the mechanism by which $1 \mathrm{D}$ materials form a 3D structure, new 1D materials can be discovered for potential applications. As the interlayer coupling energy of $2 \mathrm{D}$ materials is categorized into van der Waals (vdW) bonding and electrostatic bonding, the above-mentioned new 1D materials can also be classified accordingly: vdW bonding in $\mathrm{Sb}_{2} \mathrm{Se}_{3}$, $\mathrm{Mo}_{6} \mathrm{~S}_{9-x} \mathrm{I}_{x}$, and $\mathrm{VS}_{4}$ and electrostatic bonding by intercalated $\mathrm{Li}^{+}$ in $\mathrm{LiMo}_{3} \mathrm{Se}_{3}$. In the case of cation intercalated $1 \mathrm{D}$ materials, cations are separated in the process of dispersion, ${ }^{24}$ leaving a local negative charge defect on the surface of the $1 \mathrm{D}$ materials. ${ }^{19-23}$ On the other hand, in the case of vdW bonding, it is advantageous to obtain a high-purity 1D atomic crystal without surface defects using an appropriate synthesis process. Among the 1D materials with vdW type bonds, the synthesis, dispersion, and basic properties of $\mathrm{Mo}_{6} \mathrm{~S}_{9-x} \mathrm{I}_{x}$ have been studied to a relatively significant degree. ${ }^{26-29,31-33}$ However, the crystal structure of $\mathrm{Mo}_{6} \mathrm{~S}_{9-x} \mathrm{I}_{x}$ has not been well-defined since the positions of sulfur and iodine atoms bridged to molybdenum atoms may vary even in the same stoichiometric composition. In addition, the thermodynamic information of the ternary system (Mo, S, and I) is also lacking, which makes it difficult to understand the physical properties of $\mathrm{Mo}_{6} \mathrm{~S}_{9-x} \mathrm{I}_{x} \cdot{ }^{30}$

In this study, we have synthesized a new $1 \mathrm{D}$ bulk material with a binary system and well-defined crystal structure, $\mathrm{V}_{2} \mathrm{Se}_{9}$, in which chain-shaped molecular units with strong covalent bonds are assembled in a crystal structure via weak vdW attraction between chains. In addition, 1D materials with an inorganic molecular chain structure and dangling bond-free surface were obtained as a single-chain atomic crystal from a 3D bulk solid by the dispersion based exfoliation method (see Fig. 1a).

\section{Results and discussion}

As shown in the phase diagram in Fig. 1b, vanadium, transition metal with an outermost $3 \mathrm{~d}$ orbital, can bond with selenium in various compositions (from $\mathrm{V}_{5} \mathrm{Se}_{4}$ to $\mathrm{V}_{2} \mathrm{Se}_{9}$ ). Therefore, to synthesize a stoichiometric $\mathrm{V}_{2} \mathrm{Se}_{9}$ compound, the $\mathrm{V}$ : Se ratio and the synthesis temperature need to be carefully considered.
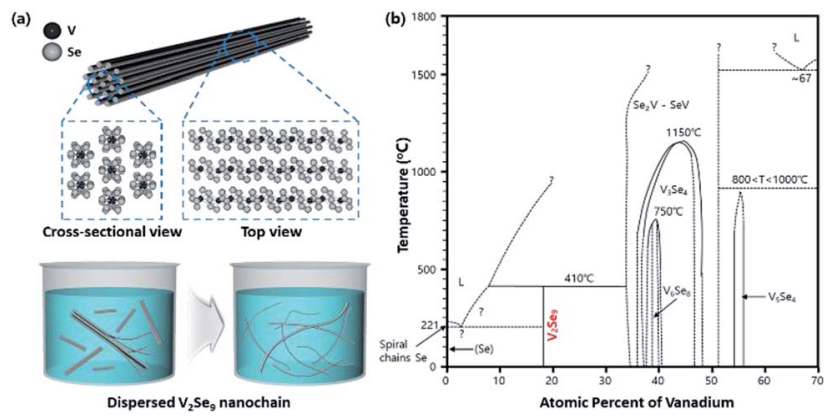

Fig. 1 (a) Crystal structure of $\mathrm{V}_{2} \mathrm{Se}_{9}$ and schematic illustration of the $\mathrm{V}_{2} \mathrm{Se}_{9}$ dispersion. (b) Phase diagram of $\mathrm{V}$-Se binary system.
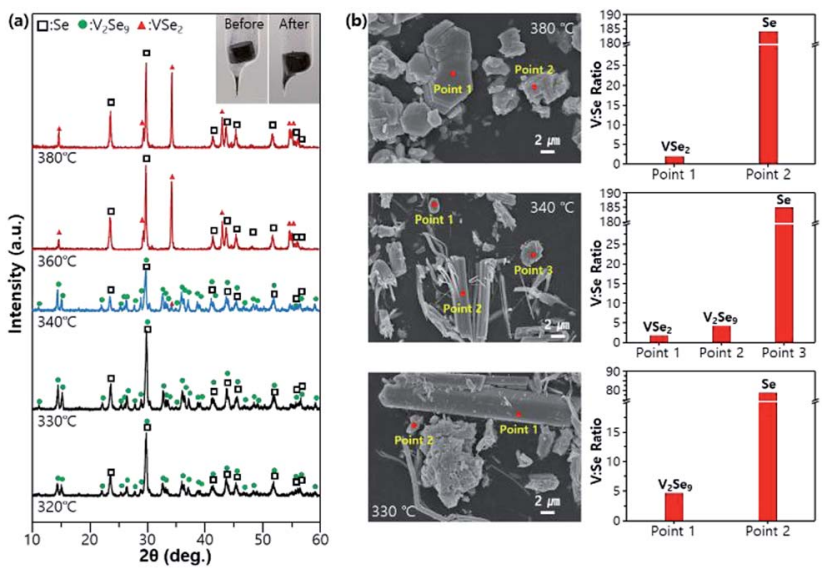

Fig. 2 (a) XRD patterns (inset is the optical images of sample before and after reaction) and (b) SEM images (left) and EDS analysis (right) of as-synthesized samples with $T$ ranging from $320^{\circ} \mathrm{C}$ to $380{ }^{\circ} \mathrm{C}$. (V: Se ratio is $2: 12.6)$.

When the synthesis of $\mathrm{V}$ and Se powders in solid form is carried out at an exact atomic mixing ratio of $2: 9$, an unwanted phase $\left(\mathrm{VSe}_{2}\right)$ can be formed at the specific interface owing to fluctuations in the V : Se ratio. Therefore, in this study, the experiment was carried out under excess Se conditions ( $\mathrm{V}:$ Se ratio of 2 : 12.6). The experimental results obtained for the exact stoichiometric ratio of $2: 9$ are shown in Fig. S2. $\dagger$

The results of X-ray diffraction (XRD) analysis of the samples synthesized at different temperatures (Fig. 2a) indicate that the $\mathrm{V}_{2} \mathrm{Se}_{9}$ phase is formed at temperatures below $330{ }^{\circ} \mathrm{C}$, whereas the $\mathrm{VSe}_{2}$ phase is formed at temperatures above $360{ }^{\circ} \mathrm{C}$ (mixed phase at $340{ }^{\circ} \mathrm{C}$ ). Scanning electron microscopy (SEM) and energy dispersive spectroscopy (EDS) were performed to analyze the structure and the composition of the materials synthesized at three specific temperatures $\left(330,340\right.$, and $\left.380^{\circ} \mathrm{C}\right)$. Using the results of XRD and EDS composition analysis, it is possible to determine the composition of the microstructural region at each temperature (Fig. $2 \mathrm{~b}$ and $\mathrm{S} 2 \dagger$ ). The $\mathrm{VSe}_{2}$ phase appears at $380^{\circ} \mathrm{C}$ and shows a layered lamellar structure, which is similar to the previously reported structure of TMDCs. ${ }^{37}$ The $\mathrm{V}_{2} \mathrm{Se}_{9}$ phase, which appears at temperatures $\leq 340{ }^{\circ} \mathrm{C}$, exhibits a $3 \mathrm{D}$ structure. However, as can be seen from the SEM images at $340{ }^{\circ} \mathrm{C}$, a part of the $\mathrm{V}_{2} \mathrm{Se}_{9}$ phase begins to partially disperse into a $1 \mathrm{D}$ structure like a thread. Furthermore, Se, which is observed at all temperatures, is dispersed in several places in the form of particles; Se can be removed by heat treatment at its sublimation temperature $\left(>221{ }^{\circ} \mathrm{C}\right) .{ }^{38}$

The remaining Se particles can be removed by sublimation (heat treatment in a tube furnace at $250{ }^{\circ} \mathrm{C}$ under Ar atmosphere for $24 \mathrm{~h}$ ). It is evident from the XRD pattern (Fig. 3a) that, Se with hexagonal crystals in the solid state can be completely removed after sublimation, and the $\mathrm{V}_{2} \mathrm{Se}_{9}$ solid crystal is exposed at the site where Se is sublimated (Fig. 3b). The thermal stability and the residual Se sublimation of $\mathrm{V}_{2} \mathrm{Se}_{9}$ were confirmed by thermogravimetric characterization using differential thermal analysis (DTA) and thermogravimetric analysis (TGA) (Fig. 3c and d). Before Se sublimation treatment, the mass decrease was about $68.1 \%$, while that after Se sublimation 

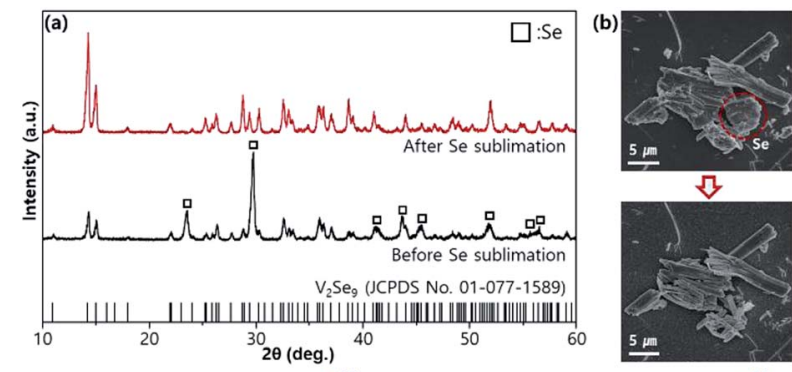
?
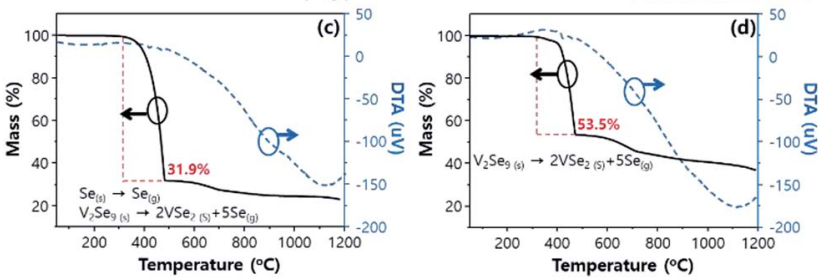

Fig. 3 Physical and chemical changes of $\mathrm{V}_{2} \mathrm{Se}_{9}$ synthesized at $330{ }^{\circ} \mathrm{C}$ after Se sublimation. (a) XRD patterns (bottom: before Se sublimation, top: after Se sublimation), (b) SEM images (top: before Se sublimation, bottom: after Se sublimation, red dashed circle is Se) and (c and d) TG/DTA analysis in $\mathrm{N}_{2}$ atmosphere (left: before Se sublimation, right: after Se sublimation, red dashed line is Se sublimation and $\mathrm{V}_{2} \mathrm{Se}_{9}$ decomposition step).

treatment was $46.5 \%$. Mass reduction occurs even after Se sublimation, because the decomposition process $\left(\mathrm{V}_{2} \mathrm{Se}_{9(\mathrm{~s})} \rightarrow\right.$ $\left.2 \mathrm{VSe}_{2(\mathrm{~s})}+5 \mathrm{Se}_{(\mathrm{g})}\right)$ happens at approximately $400{ }^{\circ} \mathrm{C}$. In other words, the $\mathrm{V}_{2} \mathrm{Se}_{9}$ samples synthesized in this experiment show stable thermal properties up to $400{ }^{\circ} \mathrm{C}$. Also, after Se sublimation, the exothermic DTA peaks at approximately $400{ }^{\circ} \mathrm{C}$ is evident along with decomposition of $\mathrm{V}_{2} \mathrm{Se}_{9}$ into $\mathrm{VSe}_{2}$ and Se. Otherwise, in the DTA curves before Se sublimation, exothermic peaks from decomposition reaction $\left(\mathrm{V}_{2} \mathrm{Se}_{9(\mathrm{~s})} \rightarrow 2 \mathrm{VSe}_{2(\mathrm{~s})}+5 \mathrm{Se}_{(\mathrm{g})}\right)$ is cancelled out by the endothermic Se sublimation reaction.
The residual-Se sublimated $\mathrm{V}_{2} \mathrm{Se}_{9}$ was dispersed into a $1 \mathrm{D}$ chain and its characteristics were analyzed. Bulk $\mathrm{V}_{2} \mathrm{Se}_{9}$ was dispersed in isopropyl alcohol (IPA) solvent and deposited on $\mathrm{Si}$ / $\mathrm{SiO}_{2}$ wafer after sonication. As shown in Fig. 4a, a distinctive Tyndall effect appears, indicating nanoscale dispersion. The dispersed $\mathrm{V}_{2} \mathrm{Se}_{9}$ in IPA were spin-coated on $\mathrm{Si} / \mathrm{SiO}_{2}$ substrates, and the size of the nano-chain was analyzed using an atomic force microscope (AFM); the results are shown in Fig. 4b. It is evident that the $1 \mathrm{D}$ structure of $\mathrm{V}_{2} \mathrm{Se}_{9}$ chains with an average size of $16 \mathrm{~nm}$ is well dispersed. IR absorption spectrum of dispersed solution is given in Fig. S3. $\dagger$ The IR absorption peak is observed at $1700 \mathrm{~nm}$ which correspond to the known bandgap of $0.73 \mathrm{eV}$ (Fig. S3†). Transmission electron microscopy (TEM) results also confirm that the $1 \mathrm{D}$ chain of size $16 \mathrm{~nm}$ exhibits a high degree of crystallinity and is well separated (Fig. 4c). It is considered that more detailed separation of $1 \mathrm{D} \mathrm{V}_{2} \mathrm{Se}_{9}$ chains into atomic units will require optimization of the dispersion solvent and the dispersion process.

\section{Experimental section}

\section{Synthesis}

Vanadium selenide $\left(\mathrm{V}_{2} \mathrm{Se}_{9}\right)$ was synthesized using $\mathrm{V}$ (powder, -325 mesh, 99.5\%, Aldrich) and Se (powder, 99+\%, Alfa Aesar) elements. The mixture of $\mathrm{V}(0.2038 \mathrm{~g})$ and Se $(1.4213$ or $1.9898 \mathrm{~g}$ for $\mathrm{V}$ : Se ratio of $2: 9$ or $2: 12.6)$ was pelletized and then sealed in a $10 \mathrm{~cm}$-long evacuated quartz tube. The quartz ampoule was heated for $120 \mathrm{~h}$ at a temperature of $300-400{ }^{\circ} \mathrm{C}\left(\right.$ at $5.5{ }^{\circ} \mathrm{C} \mathrm{h}^{-1}$ ) and then cooled (at $10{ }^{\circ} \mathrm{C} \mathrm{h}^{-1}$ ). The resulting material was a dark gray sintered powder (right inset, Fig. 2a). The unreacted Se was sublimated in a tube furnace at $250{ }^{\circ} \mathrm{C}$ under $\mathrm{Ar}$ atmosphere for $24 \mathrm{~h}$.
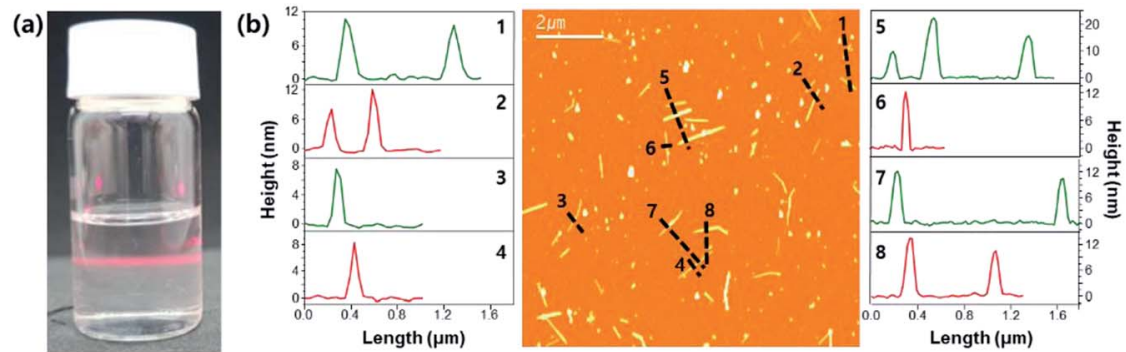

(c)
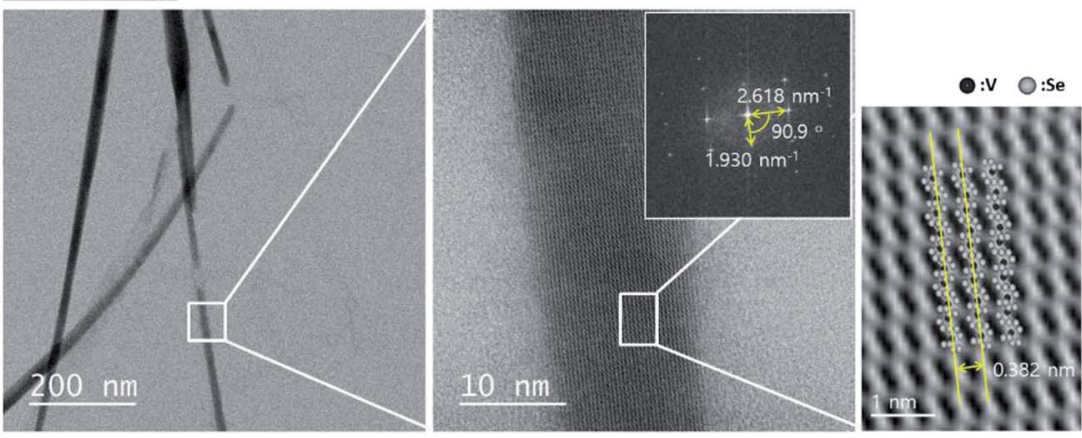

Fig. 4 Dispersion of $\mathrm{V}_{2} \mathrm{Se}_{9}$ in IPA. (a) Tyndall effect of $\mathrm{V}_{2} \mathrm{Se}_{9}$ dispersed solution. (b) AFM image of $\mathrm{V}_{2} \mathrm{Se}_{9}$ chains deposited on $\mathrm{Si} / \mathrm{SiO} \mathrm{O}_{2}$ substrate and the height profiles along each dashed line. (c) TEM images and FFT pattern (inset) of dispersed $\mathrm{V}_{2} \mathrm{Se}_{9}$ chains (the distance between two chains marked by yellow line is $0.382 \mathrm{~nm}$ ). 


\section{Dispersion}

Two milligrams of $\mathrm{V}_{2} \mathrm{Se}_{9}$ were dispersed in $20 \mathrm{~mL}$ of IPA by ultrasonication. The ultrasonication was implemented by probe sonication (VC 505, Sonics \& Materials, Inc.) for $5 \mathrm{~min}$ at a $2 \mathrm{~s} \mathrm{on} / 2 \mathrm{~s}$ off interval in order to crush the chunk powders. Then, bath sonication was implemented (B2005S-68K, 68 kHz, 200 W, KODO Technical) for $3 \mathrm{~h}$ to exfoliate the crushed bulk $\mathrm{V}_{2} \mathrm{Se}_{9}$ into nanochain as well as prevent the damage from probe sonication. ${ }^{39,40}$ After ultrasonication, centrifugation at $6000 \mathrm{rpm}$ for $10 \mathrm{~min}$ was carried out to remove the insufficiently dispersed chains. Five milliliters of the supernatant solution was used for AFM and TEM analyses.

\section{Characterization}

Powder XRD (Mac Science, M18XHF22) was performed using $\mathrm{Cu}-\mathrm{K}_{\alpha}$ radiation $(\lambda=0.154 \mathrm{~nm})$. A field-emission scanning electron microscope (FESEM, Hitachi, S-4300SE) and EDS attached to FESEM was employed for morphology and composition analysis. Thermal gravimetry differential thermal analysis (TG-DTA, Seiko Instrument Inc., TG/DTA7300) measurements were performed under $\mathrm{N}_{2}$ atmosphere up to $1200{ }^{\circ} \mathrm{C}$ (at $10{ }^{\circ} \mathrm{C} \mathrm{min}^{-1}$ ). Atomic force microscopy (AFM, Park systems, XE100 \& XE150) was operated in non-contact mode; the samples were prepared by spin coating on $\mathrm{Si} / \mathrm{SiO}_{2}$ wafer. UVvis-NIR spectroscopy (Agilent Technologies, CARY-5000) was employed for the optical property analysis. An aberrationcorrected scanning transmission electron microscope (STEM, JEOL, JEM ARM 200F) was operated at an acceleration voltage of $80 \mathrm{kV}$. The sample for STEM was prepared by drop casting on a graphene-coated Quantifoil TEM grid.

\section{Conclusions}

The synthesis and nanoscale dispersion of a new 1D material, $\mathrm{V}_{2} \mathrm{Se}_{9}$, which exhibits a molecular chain structure with a diameter up to $\sim 1 \mathrm{~nm}$, were successfully carried out. The reaction of $\mathrm{V}$ and Se was induced by the solid-state method to synthesize high purity $\mathrm{V}_{2} \mathrm{Se}_{9}$ crystals. The synthesized $\mathrm{V}_{2} \mathrm{Se}_{9}$ crystals were dispersed to obtain 1D nanochains with a size of $16 \mathrm{~nm}$ or less. The covalently bonded $\mathrm{V}_{2} \mathrm{Se}_{9}$ chain, when isolated from its $3 \mathrm{D}$ bulk material, is expected to exhibit unique quantum physical properties owing to the confinement of electrons in the $1 \mathrm{D}$ chain structure and the absence of inter-chain interactions, as demonstrated in the case of graphene and other 2D materials. ${ }^{\mathbf{1 , 2}}$ Therefore, the novel 1D material of $\mathrm{V}_{2} \mathrm{Se}_{9}$, as an extension of the current 2D material, is expected to create a new class of materials that will be of significant interest to materials science and nanotechnology communities for new device applications.

\section{Author contribution}

J. Y. C. designed the experiments, and S. O. and S. C. performed the chemical reaction experiments and B. J. K. and K. H. C. supported the elemental analysis. J. J. and Y. H. support the chemical reaction experiment and D. K. and W. S. J. and Y. M. K. supported structural analysis. H. K. Y. and J. Y. C. conceived and supervised this study and provided intellectual and technical guidance”.

\section{Conflicts of interest}

There are no conflicts to declare.

\section{Acknowledgements}

This research was supported by Nano Material Technology Development Program through the National Research Foundation of Korea (NRF) funded by Ministry of Science and ICT (2017M3A7B8065561). This work was supported by the National Research Foundation of Korea (NRF) grant funded by the Korea government (MSIP) (No. NRF-2017R1A4A1015770).

\section{References}

1 K. S. Novoselov, A. K. Geim, S. Morozov, D. Jiang, M. Katsnelson, I. Grigorieva, S. Dubonos and A. A. Firsov, Nature, 2005, 438, 197.

2 Y. Zhang, Y.-W. Tan, H. L. Stormer and P. Kim, Nature, 2005, 438, 201.

3 K. I. Bolotin, K. Sikes, Z. Jiang, M. Klima, G. Fudenberg, J. Hone, P. Kim and H. Stormer, Solid State Commun., 2008, 146, 351-355.

4 K. S. Kim, Y. Zhao, H. Jang, S. Y. Lee, J. M. Kim, K. S. Kim, J.-H. Ahn, P. Kim, J.-Y. Choi and B. H. Hong, Nature, 2009, 457, 706.

5 C. Lee, X. Wei, J. W. Kysar and J. Hone, Science, 2008, 321, 385-388.

6 G. Tai, T. Hu, Y. Zhou, X. Wang, J. Kong, T. Zeng, Y. You and Q. Wang, Angew. Chem., 2015, 127, 15693-15697.

7 T. Hu, K. Bian, G. Tai, T. Zeng, X. Wang, X. Huang, K. Xiong and K. Zhu, J. Phys. Chem. C, 2016, 120, 25843-25850.

8 Z. Wu, G. Tai, X. Wang, T. Hu, R. Wang and W. Guo, Nanotechnology, 2018, 29, 125605.

9 G. Tai, T. Zeng, J. Yu, J. Zhou, Y. You, X. Wang, H. Wu, X. Sun, T. Hu and W. Guo, Nanoscale, 2016, 8, 2234-2241.

10 B. Radisavljevic, A. Radenovic, J. Brivio, i. V. Giacometti and A. Kis, Nat. Nanotechnol., 2011, 6, 147.

11 K. F. Mak, C. Lee, J. Hone, J. Shan and T. F. Heinz, Phys. Rev. Lett., 2010, 105, 136805.

12 J. Qiao, X. Kong, Z.-X. Hu, F. Yang and W. Ji, Nat. Commun., 2014, 5, 4475.

13 A. Castellanos-Gomez, L. Vicarelli, E. Prada, J. O. Island, K. Narasimha-Acharya, S. I. Blanter, D. J. Groenendijk, M. Buscema, G. A. Steele and J. Alvarez, 2D Mater., 2014, 1, 025001.

14 F. Schwierz, Nat. Nanotechnol., 2010, 5, 487.

15 P. Avouris, M. Freitag and V. Perebeinos, Nat. Photonics, 2008, 2, 341.

16 J. Wang and M. Musameh, Anal. Chem., 2003, 75, 2075-2079.

17 Z. Chen, V. Augustyn, J. Wen, Y. Zhang, M. Shen, B. Dunn and Y. Lu, Adv. Mater., 2011, 23, 791-795.

18 M. Kusunoki, T. Suzuki, C. Honjo, T. Hirayama and N. Shibata, Chem. Phys. Lett., 2002, 366, 458-462.

19 J. H. Golden, F. J. DiSalvo, J. M. Fréchet, J. Silcox, M. Thomas and J. Elman, Science, 1996, 273, 782-784. 
20 A. Heidelberg, H. Bloess, J. Schultze, C. Booth, E. Samulski and J. Boland, Z. Phys. Chem, 2003, 217, 573-586.

21 B. Messer, J. H. Song, M. Huang, Y. Wu, F. Kim and P. Yang, Adv. Mater., 2000, 12, 1526-1528.

22 F. E. Osterloh, H. Hiramatsu, R. Dumas and K. Liu, Langmuir, 2005, 21, 9709-9713.

23 F. E. Osterloh, J. S. Martino, H. Hiramatsu and D. P. Hewitt, Nano Lett., 2003, 3, 125-129.

24 J. Tarascon, F. DiSalvo, C. Chen, P. Carroll, M. Walsh and L. Rupp, J. Solid State Chem., 1985, 58, 290-300.

25 J.-M. Tarascon, G. Hull and F. DiSalvo, Mater. Res. Bull., 1984, 19, 915-924.

26 B. Berčič, U. Pirnat, P. Kusar, D. Dvorsek, D. Mihailovic, D. Vengust and B. Podobnik, Appl. Phys. Lett., 2006, 88, 173103.

27 J. J. Doyle, V. Nicolosi, S. M. O'Flaherty, D. Vengust, A. Drury, D. Mihailovic, J. N. Coleman and W. J. Blau, Chem. Phys. Lett., 2007, 435, 109-113.

28 Z. Kutnjak, D. Vrbanić, S. Pejovnik and D. Mihailović, J. Appl. Phys., 2006, 99, 064311.

29 D. N. McCarthy, V. Nicolosi, D. Vengust, D. Mihailovic, G. Compagnini, W. J. Blau and J. N. Coleman, J. Appl. Phys., 2007, 101, 014317.

30 A. Meden, A. Kodre, J. P. Gomilšek, I. Arčon, I. Vilfan, D. Vrbanic, A. Mrzel and D. Mihailovic, Nanotechnology, 2005, 16, 1578.
31 D. Vengust, F. Pfuner, L. Degiorgi, I. Vilfan, V. Nicolosi, J. Coleman and D. Mihailovic, Phys. Rev. B: Condens. Matter Mater. Phys., 2007, 76, 075106.

32 I. Vilfan and D. Mihailovic, Phys. Rev. B: Condens. Matter Mater. Phys., 2006, 74, 235411.

33 D. Vrbanić, M. Remškar, A. Jesih, A. Mrzel, P. Umek, M. Ponikvar, B. Jančar, A. Meden, B. Novosel and S. Pejovnik, Nanotechnology, 2004, 15, 635.

34 Y. Zhou, L. Wang, S. Chen, S. Qin, X. Liu, J. Chen, D.-J. Xue, M. Luo, Y. Cao and Y. Cheng, Nat. Photonics, 2015, 9, 409.

35 X. Xu, S. Jeong, C. S. Rout, P. Oh, M. Ko, H. Kim, M. G. Kim, R. Cao, H. S. Shin and J. Cho, J. Mater. Chem. A, 2014, 2, 10847-10853.

36 S. Britto, M. Leskes, X. Hua, C.-A. Hébert, H. S. Shin, S. Clarke, O. Borkiewicz, K. W. Chapman, R. Seshadri and J. Cho, J. Am. Chem. Soc., 2015, 137, 8499-8508.

37 S. Jeong, D. Yoo, J.-t. Jang, M. Kim and J. Cheon, J. Am. Chem. Soc., 2012, 134, 18233-18236.

38 A. A. Jadhav and P. K. Khanna, RSC Adv., 2015, 5, 4475644763.

39 Y. Xing, L. Li, C. C. Chusuei and R. V. Hull, Langmuir, 2005, 21, 4185-4190.

40 U. Khan, H. Porwal, A. O'Neill, K. Nawaz, P. May and J. N. Coleman, Langmuir, 2011, 27, 9077-9082. 